\title{
Optimization of Ni-Based WC/Co/Cr Composite Coatings Produced by Multilayer Laser Cladding
}

\author{
Andrea Angelastro, Sabina L. Campanelli, Giuseppe Casalino, and Antonio D. Ludovico \\ Department of Mechanics, Mathematics and Management, Polytechnic University of Bari, Viale Japigia 182, 70126 Bari, Italy \\ Correspondence should be addressed to Sabina L. Campanelli; campanel@poliba.it
}

Received 7 January 2013; Accepted 29 April 2013

Academic Editor: Roham Rafiee

Copyright ( 2013 Andrea Angelastro et al. This is an open access article distributed under the Creative Commons Attribution License, which permits unrestricted use, distribution, and reproduction in any medium, provided the original work is properly cited.

\begin{abstract}
As a surface coating technique, laser cladding (LC) has been developed for improving wear, corrosion, and fatigue properties of mechanical components. The main advantage of this process is the capability of introducing hard particles such as $\mathrm{SiC}$, TiC, and WC as reinforcements in the metallic matrix such as Ni-based alloy, Co-based alloy, and Fe-based alloy to form ceramic-metal composite coatings, which have very high hardness and good wear resistance. In this paper, Ni-based alloy (Colmonoy 227-F) and Tungsten Carbides/Cobalt/Chromium (WC/Co/Cr) composite coatings were fabricated by the multilayer laser cladding technique (MLC). An optimization procedure was implemented to obtain the combination of process parameters that minimizes the porosity and produces good adhesion to a stainless steel substrate. The optimization procedure was worked out with a mathematical model that was supported by an experimental analysis, which studied the shape of the clad track generated by melting coaxially fed powders with a laser. Microstructural and microhardness analysis completed the set of test performed on the coatings.
\end{abstract}

\section{Introduction}

Increasing attention is given to metal matrix composites (MMC) consisting of hard and brittle carbide particles embedded in a tough metal binder. Carbide-metal matrix composite materials are characterized by a high resistance to all types of wear. It is due to a positive combination of properties given by hard phase particles included in a tough matrix, capable of reducing stresses by plastic deformation. The superior wear resistance of Tungsten Carbide and in particular of WC/ $\mathrm{W}_{2} \mathrm{C}$ or WC-Co as hardfacing material is well known, while Co- or Ni-based alloys are mostly used as binders.

Laser cladding is capable of producing a wide range of surface alloys and composites of required properties [1]. In the last years, LC has shown a growing interest due to its capability of introducing hard particles such as $\mathrm{SiC}, \mathrm{TiC}$, and $\mathrm{WC}$ as reinforcements in the metallic matrix such as Ni-based alloy, Co-based alloy, and Fe-based alloy to form the ceramicmetal composite coatings, which have very high hardness and good wear resistance [2-7].
Nickel-based alloys have a unique combination of properties that enables them to be applicable in a variety of applications. Specifically, Nickel-based alloys coatings, with high bonding strength, a better corrosion behavior, and excellent resistance to adhesive and abrasive wear, have promising applications in engineering [8].

Laser cladding with metal-WC composite coating has shown high potentiality for enhancing wear resistance since WC combines high hardness, low coefficient of thermal expansion, good plasticity, and wettability by molten metals.

Several works can be found in the literature on the laser cladding processing of Nickel-based and WC composite coatings.

Chen et al. [9] presented an investigation on laser cladding of a composite alloy powder consisting of 35\% WC particles and Ni-Cr-B-Si alloy on mild steel substrate, producing a high resistance composite coating with a strong metallurgical bond and minimal dilution.

Wu et al. [10] demonstrated that high-quality Nickelbased and 60\% WC composite coatings can be produced controlling laser cladding processing parameters. 
TABLE 1: Nominal chemical composition of the powders used in experiments.

\begin{tabular}{lcccccccc}
\hline Alloy (wt\%) & B & C & Co & Cr & Fe & Ni & Si & WC \\
\hline Colmonoy 227-F & 0.80 & 0.03 & - & 0.30 & 0.04 & Bal. & 2.51 & - \\
WC/Co/Cr (Sintered T311) & - & - & 10 & 4.0 & - & - & - & 86 \\
\hline
\end{tabular}

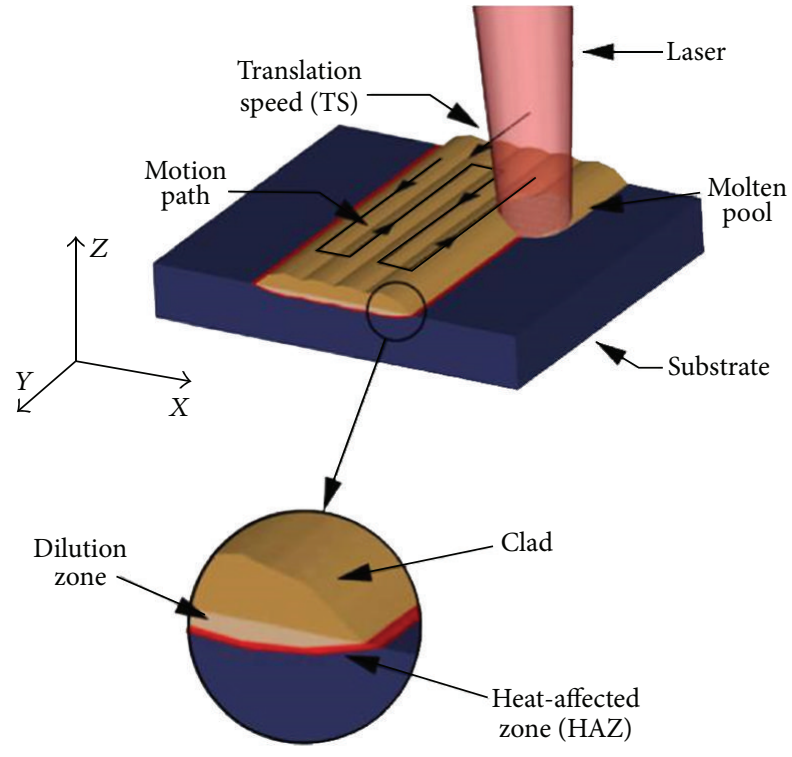

FIGURE 1: Schematic representation of the laser cladding process.

Van Acker et al. [11] explored laser cladding of Ni$\mathrm{WC} / \mathrm{W}_{2} \mathrm{C} \mathrm{MMC}$ coatings on low carbon steel substrates, using a $\mathrm{CO}_{2}$ laser. They made different coatings with three different particle sizes of the carbides and volume fractions ranging from $0 \%$ up to $50 \%$. A clear dependency of the wear resistance on the carbide concentration was found, which was more pronounced for the coatings with the finest $\mathrm{WC} / \mathrm{W}_{2} \mathrm{C}$ carbides. They found that a small amount of carbides is sufficient to improve the wear resistance drastically.

Zhou et al. [12-14] investigated the relationships between some processing parameters (i.e., laser specific energy, powder density, preheated temperature of substrate, and types of substrate) and the structure characteristics of Ni-based WC composite coatings during laser induction hybrid rapid cladding (LIHRC), finding that crack-free composite coatings with smooth surface and good profile can be prepared by LIHRC on the different substrates.

In LC, laser beam is focused and moved on the top surface of the substrate producing a molten pool where a metal powder flow is injected. Powder totally melts and then quickly resolidifies creating a track, characterized by high density and by good bonding to the substrate. The first layer is realized depositing tracks one next to the other, with a designated amount of overlap (Figure 1). After the deposition of the first layer, in multilayer laser cladding (MLC), the laser head, which includes focusing lens and powder delivery nozzle, is raised in the positive $Z$-direction and starts deposition of the second layer. Therefore, process recurs, line-by-line and layerby-layer, until the entire component is built up.
In the present investigation, the $\mathrm{Ni}$-based $\mathrm{WC} / \mathrm{Co} / \mathrm{Cr}$ composite coatings made by the multilayer laser cladding technique were studied. An optimization procedure, which used a mathematical model, was applied. The mathematical model, based on previous research studies [15-18] allowed calculating the optimal values of the laser translation speed and of the hatch spacing between adjacent vectors and between layers of the deposited material. The presented methodology allowed selecting the optimal combination of parameters that produced low porosity, crack-free, and good bond between the layers of the coatings.

\section{Materials and Methods}

2.1. Experimental Setup and Materials. A mixture of $30 \%$ Colmonoy $227-\mathrm{F}$ and $70 \% \mathrm{WC} / \mathrm{Co} / \mathrm{Cr}$ powders was used as the coating material. The composition of both powders is listed in Table 1. Colmonoy 227-F is a commercially available product of Wall Colmonoy consisting of $\mathrm{Ni}$ alloy with maximum particle diameter of $106 \mu \mathrm{m}$. This material, characterized by an elevated hardness (22-27 Rockwell C), a density of $8.53 \mathrm{~g} / \mathrm{cm}^{3}$, and a melting point of $915^{\circ} \mathrm{C}$, is able to tolerate extreme job conditions because of its elevated resistance to abrasion, corrosion, stresses, and high temperatures [19-21].

The other material is Sintered T311, commercially produced by MBN Nanomaterialia S. p. A. (maximum particle diameter $49 \mu \mathrm{m}$ ). This powder is characterized by an elevated amount of WC (about $86 \% \mathrm{wt}$ ) and by the presence of Co (10\% wt) and $\mathrm{Cr}(4 \% \mathrm{wt})$.

The substrate material consisted in AISI 304 steel.

The equipment used for cladding was a $3 \mathrm{~kW} \mathrm{CW} \mathrm{CO}_{2}$ laser system, together with a powder supply system consisting of a pneumatic conveyor, a splitter, used to mix and divide the flow into three equal flows of carrier gas and powder mixture, and, finally, a coaxial nozzle having the function to direct the three powder flows coming from the splitter in the weld pool.

In order to optimize the process parameters, a mathematical model based on previous research studies [15-18] was implemented. In detail, the model allowed calculating optimal values of translation speed of the laser beam (TS) and of hatch spacing between adjacent vectors $\left(S_{x}\right)$ and between layers $\left(S_{z}\right)$ of the deposited material (Figure 2). The other process parameters were kept constant.

The laser beam was set to $2.4 \mathrm{~kW}$ and laser spot diameter to $2 \mathrm{~mm}$. Argon was used as shielding gas with a flow rate of $12 \mathrm{~L} / \mathrm{min}$ and helium was used as carrier gas with a flow rate of $5 \mathrm{~L} / \mathrm{min}$. The powder mixture of the two kinds of materials was created in the splitter. The total powder feed rate $P_{\text {FR }}$ of the powder mixture was $9.3 \mathrm{~g} / \mathrm{min}$.

2.2. Optimization Model. The mathematical model used in this work is based on the following hypotheses [15-18]. 


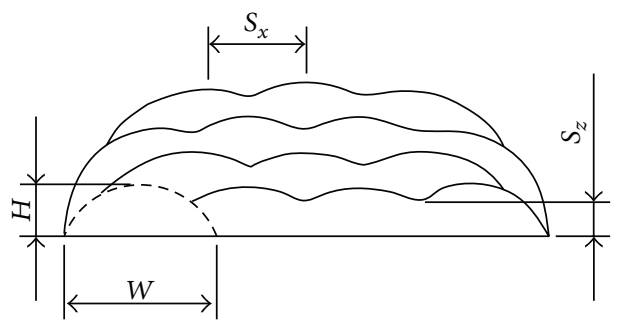

FIGURE 2: Schematic drawing of the cross-section of a deposited specimen.

(1) The deposition process is stationary: the quantity of powder at each deposited track is identical; the crosssection area of each track is uniform.

(2) The cross-section of the deposited track is geometrically similar, with some degree of approximation, to an arc of circumference of height $H$ and width $W$ (Figure 2). The area of this section is also calculated as a function of the only variable $W$, once fixed a certain value of the ratio between $H$ and $W\left(R_{H / W}\right)$. This approximation is justified, neglecting gravitational forces and the variation of the density of the melt zone with the temperature and with the concentration of alloy components. In fact, if the surface tension remains constant, the balance of forces that occurs at the interface molten zone/air ensures that its profile has radius constant $r$.

(3) The width $W$ and the deposition efficiency $\eta$ (defined as the ratio between the amount of deposited material and used powder) are linearly dependent on the translation speed TS.

Therefore, knowing the value of the density $(\rho)$ of the material to be deposited and the set of the other process parameters, including $\mathrm{PFR}_{\text {tot }}, P$, and $d$, it is possible to calculate the value of TS, to guarantee, with a small margin of error, the desired size of the cross-section of the single track.

Moreover, knowing values of $W$ and $H$, it is possible to calculate the value of the hatch spacing between adjacent tracks $\left(S_{x}\right)$, along the $X$-direction, which ensures a certain geometric regularity of the final surface of each deposited layer. Additionally, it is possible to calculate an optimal value of the hatch spacing between adjacent layers of material $\left(S_{z}\right)$, along the $Z$-direction. This value has to guarantee a degree of overlap $\left(\mathrm{O}_{\%}\right)$ which maximizes the relative density of deposited tracks and that produces a good adhesion between different layers.

In detail, according to the above hypothesis 1 , it is possible to introduce the following equation:

$$
A_{\mathrm{ABC}}=A_{\mathrm{BDEC}}=A_{\mathrm{BDFG}}=H \cdot S_{x}
$$

where $A_{\mathrm{ABC}}, A_{\mathrm{BDEC}}$, and $A_{\mathrm{BDFG}}$ are the areas of specific regions, as illustrated in Figure 3.

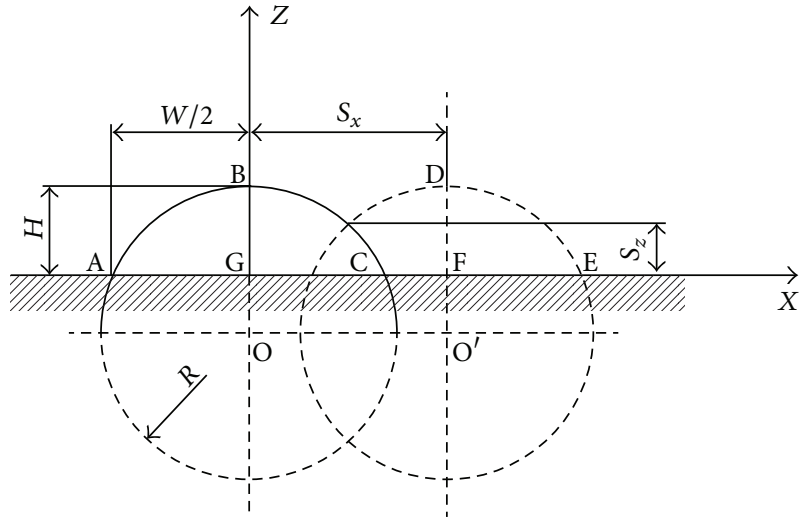

FIgURE 3: Graphic representation of the mathematical model to calculate the optimal $O_{\%}$.

In addition, it is possible to calculate the cross-sectional area $\left(\mathrm{mm}^{2}\right)$ with the following relation:

$$
\begin{aligned}
A_{\mathrm{ABC}}= & \left(\frac{(W / 2)^{2}+H^{2}}{2 \cdot H}\right)^{2} \cdot \arcsin \left(\frac{2 \cdot(W / 2) \cdot H}{(W / 2)^{2}+H^{2}}\right) \\
& -\left(\frac{W}{2}\right) \cdot \frac{(W / 2)^{2}-H^{2}}{2 \cdot H} .
\end{aligned}
$$

Finally, it is possible to obtain optimal values of $S_{x}(\mathrm{~mm})$ and of $O_{\%}$ with the following relations:

$$
\begin{gathered}
S x=\frac{A_{\mathrm{ABC}}}{H}=\frac{1}{H}\left(\frac{(W / 2)^{2}+H^{2}}{2 \cdot H}\right)^{2} \cdot \arcsin \left(\frac{2 \cdot(W / 2) \cdot H}{(W / 2)^{2}+H^{2}}\right) \\
-\left(\frac{W}{2}\right) \cdot \frac{(W / 2)^{2}-H^{2}}{2 \cdot H^{2}} \\
O_{\%}=\frac{W-S x}{W} \cdot 100
\end{gathered}
$$

According to Zhang et al. [16], the best results can be obtained for values of $R_{H / W}$ lower than a critical value $H_{c}=$ $1 / 3$, as shown in the following:

$$
R_{H / W}=\frac{H}{W} \leq H_{c}=\frac{1}{3} .
$$

2.3. Calculation of the Model Coefficients. The hypothesis of linear dependence of the width $W$ on the translation speed TS can be demonstrated by means of (6) [16]:

$$
W(\mathrm{TS})=a_{w} \cdot \mathrm{TS}+b_{w}
$$

Single-track clads were realized by LC on three AISI 304 plane substrates (Figure 4) in order to estimate the coefficients $a_{w}$ and $b_{w}$.

Three values of the translation speed TS were chosen (500-750-1000 $\mathrm{mm} / \mathrm{min}$ ) to perform the three single-track clads shown in Figure 4 . Then, the single-track widths $W_{i}$ 


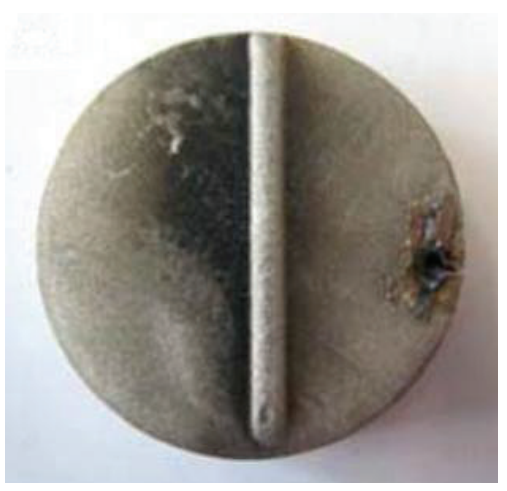

(a)

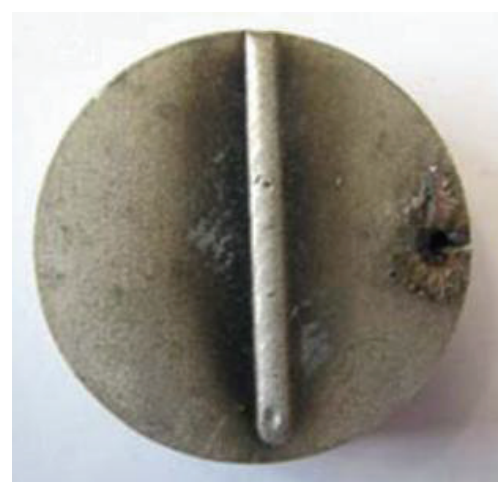

(b)

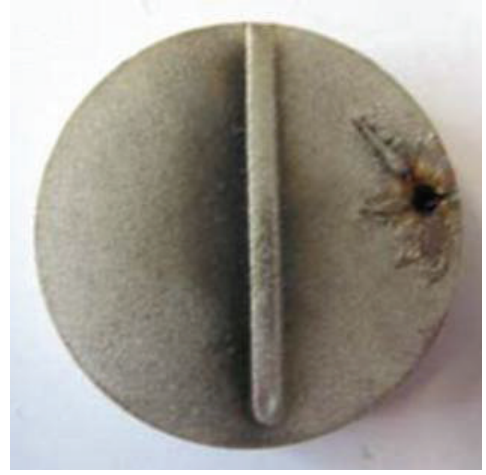

(c)

FIGURE 4: Samples made to detect the single-track clads widths $W_{i}$ at different translation speeds.

TABLE 2: Single-track clad width values obtained at different translation speeds.

\begin{tabular}{lcc}
\hline$W_{1}(\mathrm{~mm})$ & $W_{2}(\mathrm{~mm})$ & $W_{3}(\mathrm{~mm})$ \\
\hline 3.30 & 2.51 & 2.42 \\
\hline
\end{tabular}

were measured. Their values, shown in Table 2, allowed to calculate $a_{w}$ and $b_{w}$ :

$$
W=-1.76 \cdot 10^{-3} \cdot \mathrm{TS}+4.06 .
$$

The same process parameters were used to create other three samples, obtained by depositing six clads of the composite material on the AISI 304 substrate. The purpose was to obtain the coefficients $\left(a_{\eta}, b_{\eta}\right)$ of $(8)$, which shows the linear dependence of the deposition efficiency $\eta$ on the translation speed TS:

$$
\eta(\mathrm{TS})=a_{\eta} \cdot \mathrm{TS}+b_{\eta}
$$

The masses of the deposited material and of the feed powder were derived, for each sample, from (9) and (10), respectively:

$$
\begin{gathered}
M_{\text {deposit }}=M_{\text {tot }}-M_{\text {substrate }}, \\
M_{\text {powder }}=\frac{\mathrm{PFR}_{\text {tot }}}{\mathrm{TS}} \cdot L_{\text {tot }},
\end{gathered}
$$

where $M_{\text {tot }}(\mathrm{g})$ is the total mass measured by weighing the sample after the laser deposition, $M_{\text {substrate }}(\mathrm{g})$ is the plate weight measured before the laser deposition, and $L_{\text {tot }}(\mathrm{mm})$ is the total length of the six clads. Hence, it was possible to calculate the average deposition efficiency $\eta$ as follows:

$$
\eta=\frac{M_{\text {deposit }}}{M_{\text {powder }}}
$$
using

The results in Table 3 allowed calculating both $a_{\eta}$ and $b_{\eta}$

$$
\eta=-2.69 \cdot 10^{-4} \cdot \mathrm{TS}+0.755
$$

2.4. Calculation of the Optimal Translation Speed. The density of the powder mixture $\left(\rho_{\text {mix }}\right)$ was calculated by (13) as the sum between the weighted average densities of the two powders, adopted as their weights $\mathrm{wt} \%$ within the mixture:

$$
\rho_{\text {mix }}=\frac{\rho_{\mathrm{Col}} \cdot \%_{\mathrm{Col}}}{100}+\frac{\rho_{\mathrm{T} 311} \cdot \%_{\mathrm{T} 311}}{100}\left[\mathrm{~g} / \mathrm{cm}^{3}\right] .
$$

A value of $12.2 \mathrm{~g} / \mathrm{cm}^{3}$ was found for $\rho_{\text {mix }}$.

Equation (14) [15] shows the relationship between the powder feed rate $\mathrm{PFR}_{\text {tot }}(\mathrm{g} / \mathrm{min})$, the density $\rho_{\text {mix }}$, the clad cross-section area $A$, and the deposition efficiency $\eta$ :

$$
\mathrm{PFR}_{\mathrm{tot}}=\frac{\rho_{\mathrm{mix}} \cdot \mathrm{TS} \cdot A}{\eta \cdot 1000}
$$

The clad cross-section area $A\left(\mathrm{~mm}^{2}\right)$, defined by (2), can be expressed as a function of $W$ and $R_{H / W}$, as indicated in the following:

$$
\begin{aligned}
A= & {\left[\frac{W}{2 \cdot R_{H / W}} \cdot\left(\frac{1}{4}+R_{H / W}^{2}\right)\right]^{2} \cdot \arcsin \left(\frac{R_{H / W}}{1 / 4+R_{H / W}^{2}}\right) } \\
& -\frac{W^{2}}{4 \cdot R_{H / W}} \cdot\left(\frac{1}{4}-R_{H / W}^{2}\right) .
\end{aligned}
$$

The $R_{H / W}$ was set at the value $1 / 3$, as indicated in the following:

$$
R_{H / W}=\frac{H}{W}=\frac{1}{3}
$$

Finally, after setting values of $\operatorname{PFR}_{\text {tot }}(9.3 \mathrm{~g} / \mathrm{min})$ and of $\rho_{\text {mix }}\left(12.2 \mathrm{~g} / \mathrm{cm}^{3}\right)$ and solving the system of (7), (12), (14), (15), and (16), the optimal TS value was discovered (TS = $170 \mathrm{~mm} / \mathrm{min})$.

Later on, in order to check the mathematical model validity, a single clad was produced setting $P=2.4 \mathrm{~kW}$, $\mathrm{PFR}_{\mathrm{tot}}=9.3 \mathrm{~g} / \mathrm{min}$, and TS $=170 \mathrm{~mm} / \mathrm{min}$. The real height $H$ and the width $W$ of the single clad were measured, and the experimental value $R_{H / W}=0.37$ was found. This value was 
TABle 3: Average deposition efficiency $\eta$ at different translation speeds.

\begin{tabular}{lccccrr}
\hline TS $(\mathrm{mm} / \mathrm{min})$ & $L_{\text {tot }}(\mathrm{mm})$ & $M_{\text {sub }}(\mathrm{g})$ & $M_{\text {tot }}(\mathrm{g})$ & $M_{\text {dep }}(\mathrm{g})$ & $M_{\text {powder }}(\mathrm{g})$ & 11.20 \\
\hline 500 & 602.16 & 324.00 & 331.00 & 7.00 & 4.50 & 7.46 \\
750 & 601.68 & 325.50 & 330.00 & 328.50 & 2.75 & 0.62 \\
1000 & 603.00 & 325.75 & 3.61 & 0.49 \\
\hline
\end{tabular}

TABLE 4: Comparison between the experimental $R_{H / W}$ value and the set theoretical one.

\begin{tabular}{lcccccc}
\hline$H_{(\mathrm{calc})}(\mathrm{mm})$ & $W_{\text {(calc) }}(\mathrm{mm})$ & $R_{H / W(\text { calc })}$ & $H(\mathrm{~mm})$ & $W(\mathrm{~mm})$ & $R_{H / W}$ & $E_{\%}$ \\
\hline 1.25 & 3.75 & $1 / 3$ & 1.33 & 3.60 & 0.37 & 9.9 \\
\hline
\end{tabular}

TABle 5: Process and geometrical parameters.

\begin{tabular}{|c|c|c|c|c|c|c|c|}
\hline $\begin{array}{l}P \\
(\mathrm{~W}) \\
\end{array}$ & $\begin{array}{l}\mathrm{PFR}_{\text {tot }} \\
(\mathrm{g} / \mathrm{min})\end{array}$ & $\begin{array}{c}\mathrm{TS} \\
(\mathrm{mm} / \mathrm{min})\end{array}$ & $\begin{array}{c}S_{x} \\
(\mathrm{~mm})\end{array}$ & $\begin{array}{c}S_{z} \\
(\mathrm{~mm})\end{array}$ & $\begin{array}{c}\text { Number of tracks } \\
\text { (odd layers) }\end{array}$ & $\begin{array}{c}\text { Number of tracks } \\
\text { (even layers) }\end{array}$ & $\begin{array}{c}\text { Number of } \\
\text { layers }\end{array}$ \\
\hline 2400 & 9.3 & 170 & 2.65 & 0.79 & 4 & 3 & 4 \\
\hline
\end{tabular}

compared with the theoretical value $R_{H / W(\text { calc })}=1 / 3(16)$, and the percentage error $E_{\%}$, defined by (17), was calculated and found to be equal to $9.9 \%$. Results are shown in Table 4 :

$$
E_{\%}=\frac{\left|R_{H / W(\text { calc })}-R_{H / W}\right|}{R_{H / W}} \cdot 100
$$

Since the percentage error $E_{\%}$ was maintained below $10 \%$, the mathematical model was considered reliable. This result is in line with the one found by Angelastro et al. [17] that used the same methodology to determine optimal deposition parameters for Colmonoy 227-F, determining a percentage error $E_{\%}$ of $7.4 \%$.

2.5. Multilayer Composite Sample Fabrication. A multilayer sample, consisting in the LC deposition of four layers of the composite powders on AISI 304 steel substrate, was prepared. Every layer consisted of tracks all parallel to each other; in detail the first and the third layers (odd layers) were produced by four tracks and the second and the fourth layers (even layers) by three tracks.

The optimal process parameters, derived from the previous mathematical analysis, were used for the fabrication of the sample. The optimal geometrical parameters, consisting in determining values of hatch spacing $S_{x}(\mathrm{~mm})$ and $S_{z}$ $(\mathrm{mm})$, defined in Figure 3, were calculated by $(18)(R$ is the circumference radius). Process and geometrical parameters used in the fabrication of the multilayer composite sample are summarized in Table 5.

$$
\begin{gathered}
S_{x}=\frac{A_{\mathrm{ABC}}}{H}, \\
R=\frac{1}{2 \cdot H}\left(\frac{W^{2}}{4}+H^{2}\right), \\
S_{z}=\sqrt{R^{2}-\left(\frac{S_{x}}{2}\right)^{2}}-R+H .
\end{gathered}
$$

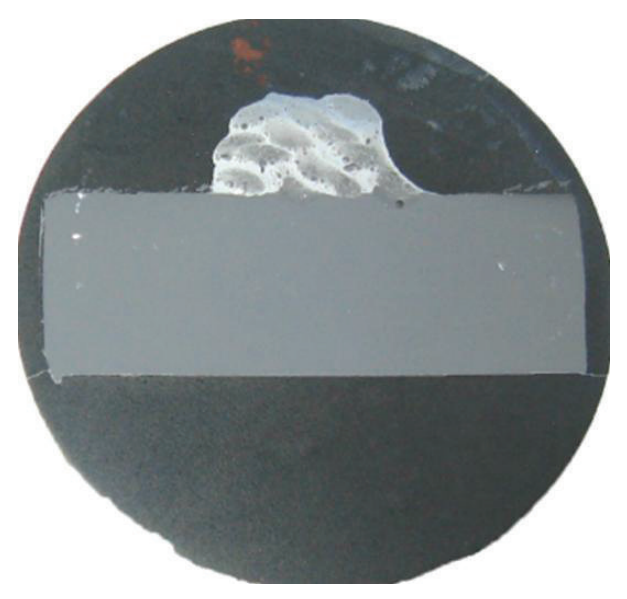

Figure 5: Sample section view.

\section{Analysis of Results}

The implementation on an analytical model allowed determining the optimal translation speed and hatch distances between adjacent vectors $\left(S_{x}\right)$ and between layers $\left(S_{z}\right)$ to obtain well-shaped multilayer composite deposits on a stainless steel substrate.

The multilayer sample was cut, polished, and etched for macro- and microstructure examinations along the transverse cross-section. An optical microscope was used to analyse the macro- and microstructure of the sample.

The macrostructure of the transverse cross-section is presented in Figure 5. The macrostructure of the cross-section reveals a pattern of layer-by-layer deposition. Moreover the deposited material appears free of cracks and with a limited number of pores. Specifically, the analysis of porosity was performed using an image processing software. A maximum porosity of $0.24 \%$ was found with an average pore diameter of $0.29 \mathrm{~mm}$.

The interface with the AISI 304 substrate was wavy and showed metallurgical bonding (Figure 6(a)). 


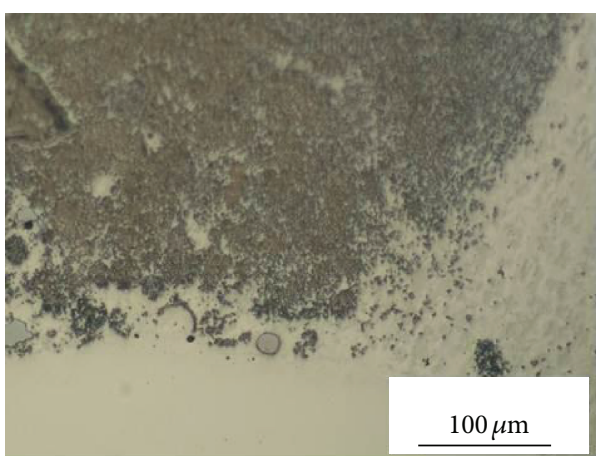

(a)

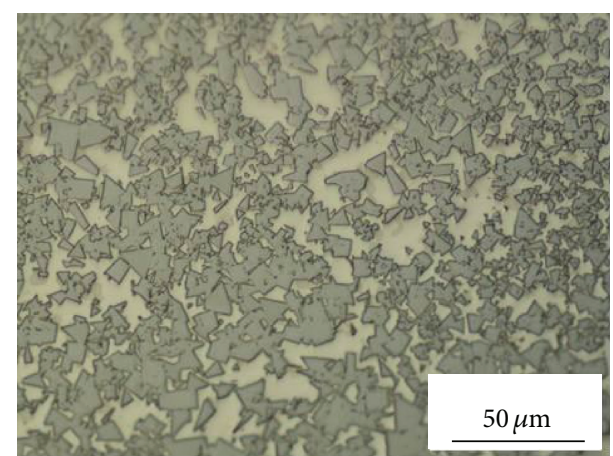

(b)

FIgURE 6: (a) Interface between the deposited material and the AISI 304 substrate (200x magnification); (b) microstructure of the deposited material (400x magnification).

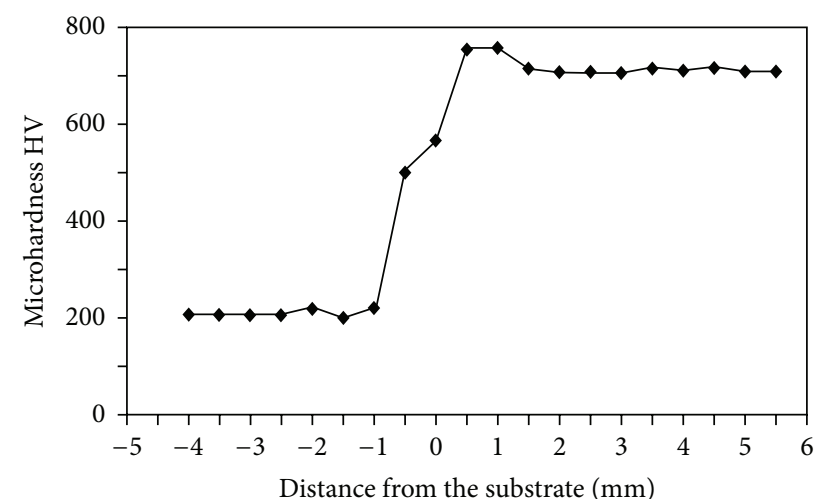

Figure 7: Microhardness profile of the multilayer laser cladding deposit.

Figure 6(b) shows the image of the $30 \%$ Colmonoy-70\% T311 laser cladding. It can be seen that there is a matrix of Cobalt and Nickel that separates the carbide particles. The sharp edges of the WC are clearly visible. The distribution of WC particles in the matrix is uniform.

The average microhardness of the deposited composite material was measured at various locations along the transversal section of the sample using a Vickers indenter Remet HX1000 applying a $300 \mathrm{gf}$ load for 15 s. Figure 7 shows the microhardness profile along the cross-section of the deposited layers on the base metal. It can be seen that the average microhardness of the bulk composite coating (approximately $700-720 \mathrm{HV}$ ) is about 3.5 times as much high as that of the stainless steel substrate (approximately $206 \mathrm{HV}$ ). The increase of the hardness can be attributed to the formation of WC hard phases, which are homogeneously dispersed in the matrix.

\section{Conclusion}

Ni-based alloy (Colmonoy 227-F) and Tungsten Carbides/ Cobalt/Chromium (WC/Co/Cr) composite coatings were fabricated by MLC on AISI 304 steel substrate. A mathematical model was used to calculate optimal values of the laser beam translation speed (TS) and of the hatch spacing between adjacent vectors $\left(S_{x}\right)$ and between layers of the deposited material $\left(S_{z}\right)$.

A uniform distribution of WC particles was observed in the matrix of Cobalt and Nickel, which allowed reaching a microhardness of approximately 700-720 HV in the composite laid down material. The increase in the hardness profile was attributed to the formation of a hard phase during the laser cladding process.

The deposited layer had a maximum porosity of $0.24 \%$. The composite coating was crack-free and characterized by good adhesion with the substrate and between layers.

\section{References}

[1] J. Przybylowicz and J. Kusiński, "Structure of laser cladded tungsten carbide composite coatings," Journal of Materials Processing Technology, vol. 109, no. 1-2, pp. 154-160, 2001.

[2] S. W. Huang, M. Samandi, and M. Brandt, "Abrasive wear performance and microstructure of laser clad WC/Ni layers," Wear, vol. 256, no. 11-12, pp. 1095-1105, 2004.

[3] G. Xu, M. Kutsuna, Z. Liu, and L. Sun, "Characteristic behaviours of clad layer by a multi-layer laser cladding with powder mixture of Stellite- 6 and tungsten carbide," Surface \& Coatings Technology, vol. 201, no. 6, pp. 3385-3392, 2006.

[4] W. Liu, M. Zhong, M. Ma, J. He, H. Zhang, and W. Zhang, "Laser producing particulate reinforced Fe-based MMC coatings and industrial applications," in Proceedinga of the 22nd ICALEO Conference on Laser Materials Processing, vol. 22, pp. 189-196, Laser Institute of America, 2003.

[5] L. Sexton, S. Lavin, G. Byrne, and A. Kennedy, "Laser cladding of aerospace materials," Journal of Materials Processing Technology, vol. 122, no. 1, pp. 63-68, 2002.

[6] L. Shepeleva, B. Medres, W. D. Kaplan, M. Bamberger, and A. Weisheit, "Laser cladding of turbine blades," Surface and Coatings Technology, vol. 125, no. 1-3, pp. 45-48, 2000.

[7] S. Zhou and X. Dai, "Laser induction hybrid rapid cladding of WC particles reinforced NiCrBSi composite coatings," Applied Surface Science, vol. 256, no. 14, pp. 4708-4714, 2010.

[8] C. Guo, J. Zhou, J. Chen, J. Zhao, Y. Yu, and H. Zhou, "High temperature wear resistance of laser cladding $\mathrm{NiCrBSi}$ and NiCrBSi/WC-Ni composite coatings," Wear, vol. 270, no. 7-8, pp. 492-498, 2011. 
[9] Z. Chen, L. C. Lim, and M. Qian, "Laser cladding of WC-Ni composite," Journal of Materials Processing Technology, vol. 62, no. 4, pp. 321-323, 1996.

[10] P. Wu, H. M. Du, X. L. Chen, Z. Q. Li, H. L. . Bai, and E. Y. Jiang, "Influence of WC particle behavior on the wear resistance properties of Ni-WC composite coatings," Wear, vol. 257, pp. 142-147, 2004.

[11] K. van Acker, D. Vanhoyweghen, R. Persoons, and J. Vangrunderbeek, "Influence of tungsten carbide particle size and distribution on the wear resistance of laser clad WC/Ni coatings," Wear, vol. 258, no. 1-4, pp. 194-202, 2005.

[12] S. Zhou, X. Zeng, Q. Hu, and Y. Huang, "Analysis of crack behavior for Ni-based WC composite coatings by laser cladding and crack-free realization," Applied Surface Science, vol. 255, no. 5, pp. 1646-1653, 2008.

[13] S. Zhou, Y. Huang, X. Zeng, and Q. Hu, "Microstructure characteristics of Ni-based WC composite coatings by laser induction hybrid rapid cladding," Materials Science and Engineering A, vol. 480, no. 1-2, pp. 564-572, 2008.

[14] S. Zhou, X. Dai, and X. Zeng, "Effects of processing parameters on structure of Ni-based WC composite coatings during laser induction hybrid rapid cladding," Applied Surface Science, vol. 255, no. 20, pp. 8494-8500, 2009.

[15] R. Colaço, L. Costa, R. Guerra, and R. Vilar, "A simple correlation between the geometry of laser cladding tracks and the process parameters," in Laser Processing: Surface Treatment and Film Deposition, J. Mazumder, O. Conde, R. Vilar, and W. Steen, Eds., pp. 421-429, Kluwer Academic Publishers, Dordrecht, The Netherlands, 1996.

[16] K. Zhang, W. Liu, and X. Shang, "Research on the processing experiments of laser metal deposition shaping," Optics \& Laser Technology, vol. 39, no. 3, pp. 549-557, 2007.

[17] A. Angelastro, S. L. Campanelli, G. Casalino, A. D. Ludovico, and S. Ferrara, "A methodology for optimization of the Direct Laser Metal Deposition process," Key Engineering Materials, vol. 473, pp. 75-82, 2011.

[18] O. C. Mazumder, R. Villar, and W. Steen, Laser Processing: Surface Treatment and Film Deposition, Springer, Berlin, Germany, 1996.

[19] A. Angelastro, S. L. Campanelli, and A. D. Ludovico, "Characterization of colmonoy 227-F samples obtained by direct laser metal deposition," in Advanced Materials Research, M. S. J. Hashmi, B. S. Yilbas, and S. Naher, Eds., vol. 83-86, pp. 842849, Trans Tech Publications, Zurich, Switzerland, 2010.

[20] M. Qian, L. C. Lim, and Z. D. Chen, "Laser cladding of nickelbased hard-facing alloys," Surface and Coatings Technology, vol. 106, no. 2-3, pp. 174-182, 1998.

[21] M. Qian, L. C. Lim, Z. D. Chen, and W. L. Chen, "Parametric studies of laser cladding processes," Journal of Materials Processing Technology, vol. 63, no. 1-3, pp. 590-593, 1997. 

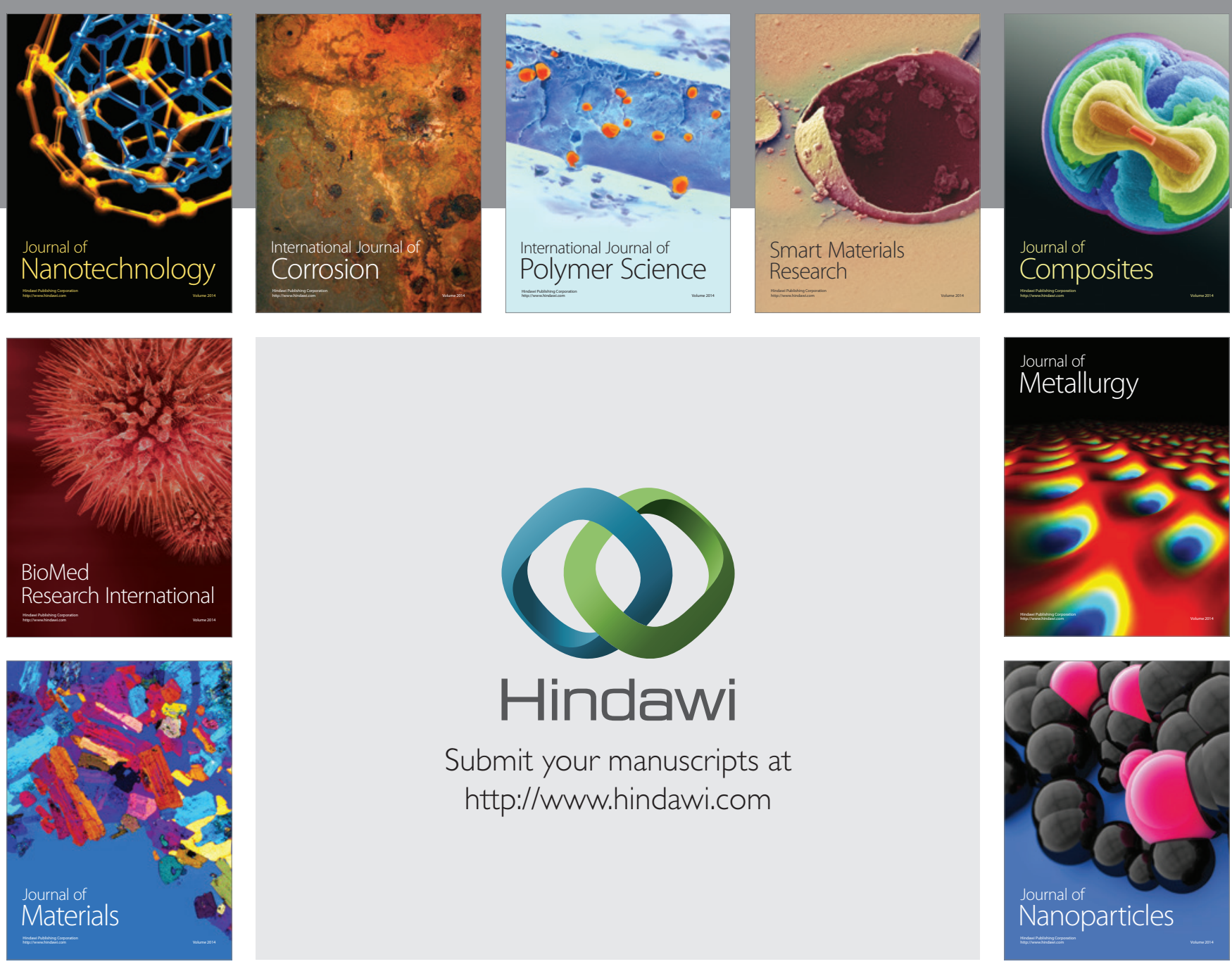

Submit your manuscripts at http://www.hindawi.com
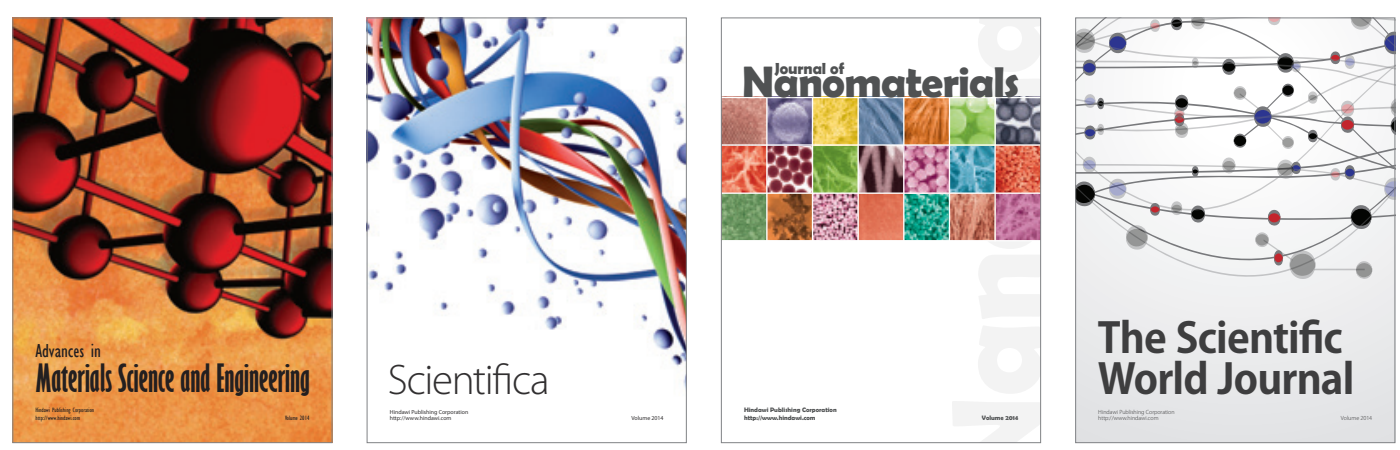

\section{The Scientific World Journal}
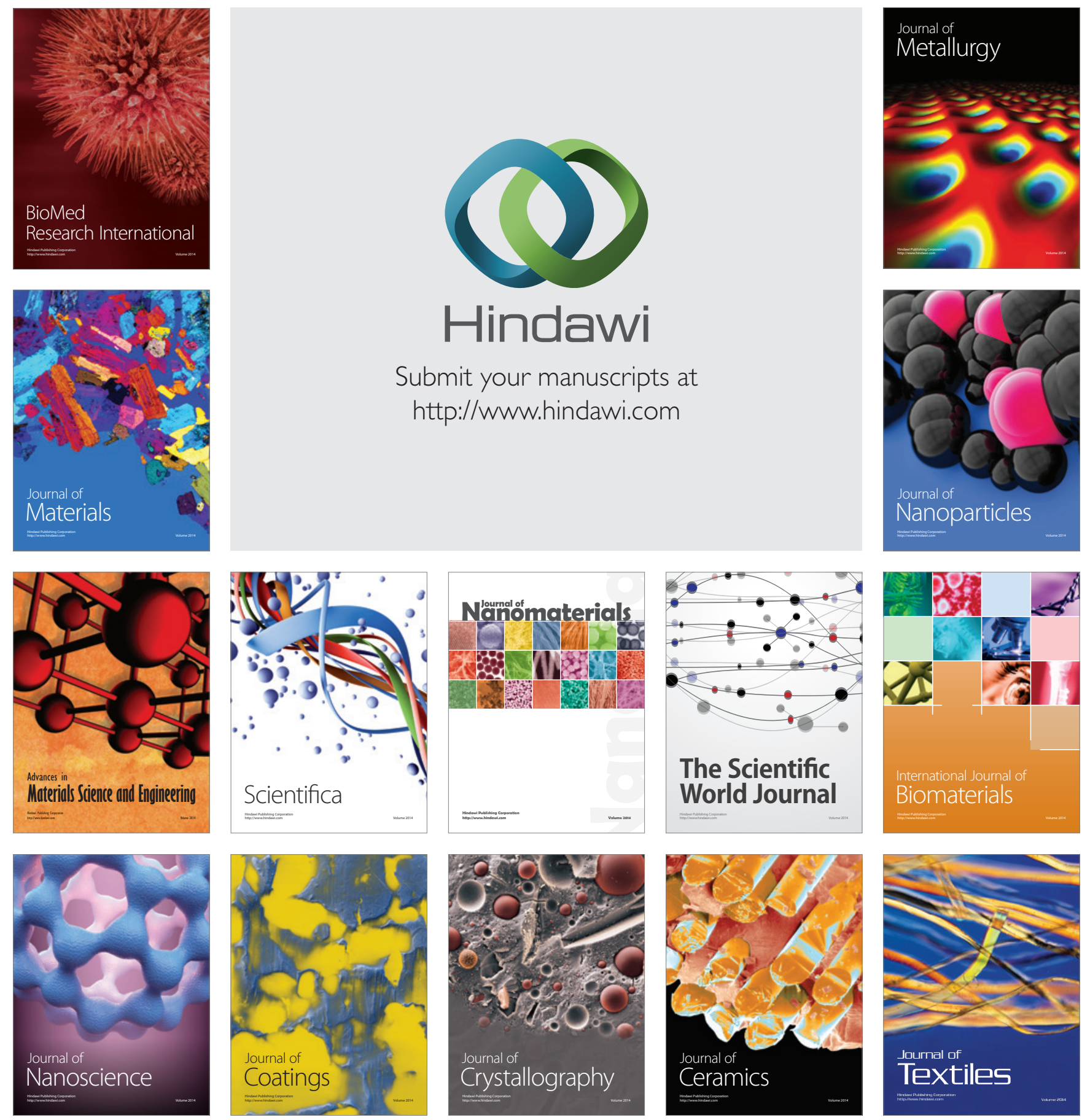